\title{
SITE AMELIORATION FOR DIRECT SEEDING OF CALADENIA TENTACULATA IMPROVES SEEDLING RECRUITMENT AND SURVIVAL IN NATURAL HABITAT
}

\author{
Magali Wright ${ }^{1,4}$, Garry French ${ }^{2}$, Rob Cross $^{3}$, Roger Cousens ${ }^{1}$, \\ SASCHA ANDRUSIAK ${ }^{1} \&$ CASSANDRA B. MCLEAN ${ }^{1}$ \\ ${ }^{1}$ School of Resource Management, Burnley Campus, The University of Melbourne, 500 Yarra Boulevard \\ Richmond, Victoria, 3121, Australia \\ ${ }^{2}$ Parks Victoria,40 Gordons Road, South Morang, Victoria, 3752, Australia \\ ${ }^{3}$ Royal Botanic Gardens Melbourne, Birdwood Avenue, South Yarra, Victoria 3141 Australia \\ ${ }^{4}$ Author for correspondence:m.wright2@pgrad.unimelb.edu.au
}

KeY WoRds: in situ seed germination, site amelioration, Caladenia

The genus Caladenia contains the largest number of threatened orchid species in Australia and improving the success of re-introductions would allow existing populations to be strengthened and new populations to be established. Batty et al. (2006) showed that direct seeding of C. arenicola Hopper \& A.P. Br. into habitat soil inoculated with mycorrhizal fungus resulted in a good in situ germination rates. However, these seedlings did not survive the summer dormancy. In Victoria, there have been successes with conservation of endangered Caladenia species using direct seeding and intensive site management (Jeanes and Backhouse 2000). Successes in these instances have been attributed to the following site amelioration treatments: soil disturbance, addition of organic matter to in situ soil and supplementary watering. It is possible that all of these treatments have contributed to successful seedling recruitment and survival. However, due to the species in these cases being endangered, little seed has been available for scientific experimentation and it has been difficult to tease out which treatments singly or in combination, provide optimum conditions for seed germination and seedling survival.

\section{Caladenia amoena: a critically endangered orchid}

Over a period of four years, a site in a public reserve was prepared for a translocation of C. amoena D.L. Jones from a remnant population on nearby private land. The proposed translocation site was steeply sloped and had suffered from topsoil erosion caused by high grazing pressure and herbivore traffic. The site was fenced and prepared by building up a flattened ledge to trap moisture from natural rainfall and the addition of natural organic matter over the four year period. In May 2004, 15 adult C. amoena plants were translocated to the site. The soil was loosened to a depth of $8 \mathrm{~cm}$ to allow planting of the soil plugs containing the plants. Seed was also sown into this loosened soil. The translocated plants and emergent seedlings were watered, by misting, when site conditions were dry. Seed has been sown around the translocated plants each year from 2004 to 2006. In the subsequent years following translocation soil was disturbed to a depth of $25 \mathrm{~mm}$ at each seed sowing.

In August 2004, 26 seedlings emerged and remained above ground for 12 weeks. Of these seedlings, $83 \%$ survived to emerge in 2005 . Ten new seedlings emerged in August 2005 and remained above ground for 10 weeks. Only $40 \%$ of them survived to emerge in 2006. Seedlings with leaf lengths under $10 \mathrm{~mm}$ rarely survived in either year. The mean leaf length was $15.8 \mathrm{~mm}$ for the seedlings that survived and $8 \mathrm{~mm}$ for those that did not. Ten new seedlings emerged in 2006 and remained above ground for only eight weeks. The percentage survival of these seedlings will be calculated when they emerge in 2007. It is suspected that less than $40 \%$ will survive, as it appears that the shorter the growing season of the new seedlings, the fewer of them sur- 
vive. The growing season of the new seedlings has dropped by two weeks every year from 2004 to 2006. This may be due to increasingly drier site conditions during each consecutive year of a prolonged drought experienced in south-eastern Australia.

\section{Caladenia tentaculata: a relatively common species}

In 2004, experimental plots in the natural habitat of C. tentaculata Schltdl. were tested in the absence of adult plants for the occurrence of mycorrhizal fungi by seed baiting (Rasmussen and Whigham 1993). As it has been shown that mycorrhizal fungi occurs around adult orchid plants (Perkins and McGee 1995, Batty et al. 2001, Ilyes et al. 2005), seed baits were buried along transects through three nearby populations of C. tentaculata as positive controls. Positive seed baits were only exhumed from one of the three transects, which was through a population of $C$. tentaculata in a site with a thick layer of Banskia marginata vegetative litter. The other two transects were located in populations which lacked any substantial litter layer. Batty et al. (2001) found that distribution of positive germinates in seed baiting experiments in Western Australia were correlated with the presence of leaf litter. They suggested that the presence of leaf litter may increase soil moisture and provide the mycorrhizal fungi with a suitable substrate. The in situ seed baiting method (Rasmussen and Whigham 1993) does not only test for the presence of mycorrhizal fungi, but also whether the soil environment is appropriate for natural seed germination.

Only 8 of 800 baits exhumed from the experimental plots were positive and were they randomly distributed. These results indicated that either there was little naturally occurring mycorrhiza present or that the conditions in the experimental plots did not enhance seed germination. As Batty (2001) had shown that the in situ seed germination rate increased with amount of mycorrhizal inoculum, the decision was made to inoculate the plots with mycorrhizal fungi when direct seeding. A mycorrhizal fungus was isolated from an adult plant in the vicinity (as in Rasmussen et al. 1990), shown to germinate C. tentaculata seed in vitro (as in Clements et al. 1986), and then used to inoculate sterilised millet seed. Seed germination was also successfully tested in vitro using infected millet seed as an inoculum. In May 2005, the experimental plots were ameliorated by adding naturally occurring organic matter, disturbing the soil and watering to supplement monthly average rainfall. The treatments used in this study included each of the three amelioration types alone and in every combination with a negative control of no amelioration. The experimental treatments were randomised according to site conditions and the mean percentage imbibition of the seed in each experimental plot as calculated in the 2004 seed baiting experiment.

After 19 weeks 56 seedlings emerged and their leaf lengths and widths were measured fortnightly during their 10 week growing season. The mean maximum leaf length reached was $8.5 \mathrm{~mm}$. Initial analysis revealed that the mean number of emergent seedlings in the plots subjected to all three amelioration types (3 seedlings) was significantly greater than that in the negative control plots ( 0 seedlings). This result clearly indicates that in situ seedling recruitment is enhanced by site amelioration. Further analysis of the data showed that there was a significant effect of soil disturbance on seedling emergence $(\mathrm{p}=0.03)$ and evidence of an effect of addition of organic matter $(\mathrm{p}=0.09)$. The analysis showed no significant effect of watering to supplement monthly rainfall. In Victorian bush land habitats soil compaction has been recognised as a problem threatening orchid populations (Backhouse and Jeanes 1995). The results of this study show that relieving soil compaction through disturbance enhances orchid seedling recruitment in situ.

In $2006,16 \%$ of the seedlings emerged after the summer dormancy. The mean maximum leaf length reached in 2005 by the surviving seedlings was 11.1 $\mathrm{mm}$, where it was $8.0 \mathrm{~mm}$ for the seedlings that did not survive. All but one of the second year seedlings emerged in plots with soil disturbance as one of the site amelioration types. Although not enough seedlings survived to conduct statistical analysis on the effect of the treatments on survival it is likely that soil disturbance was a critical factor. Soil disturbance may allow seedlings to germinate deeper in the soil profile and/or increased their dropper (tuber stalk) length. Both of these factors would result in first year tubers developing deeper in the soil than those growing in non-disturbed treatments. Tubers that are deeper in the soil profile would have more protection from desiccation during the summer dormancy. 


\section{Conclusions}

This study has shown, for the first time that in situ seedling recruitment of Caladenia species can be improved by site amelioration. Soil disturbance was the most effective treatment at improving recruitment of $C$. tentaculata in situ. There was evidence that soil disturbance also improved seedling survival during the summer dormancy. The leaf length reached by new seedlings in their first year of growth and the length of their growing season also effected their subsequent survival. This information will directly benefit the conservation and reintroduction of Australia's most endangered genus.

ACKNOWLEDGMENTS. We would like to acknowledge Dr. Graham Hepworth for assistance with experimental design and statistical analysis. This study could not have been possible without local rain water supplied by Steven and Lina Murphy for the supplementary watering in a drought. We also acknowledge the advice and observations of Cam Beardsell and Andrew Pritchard; and the generous funding of the Australian Orchid Foundation, the Department of Sustainability and Environment, The Natural Heritage Trust, the E.A. Crespin Scholarship, the J.M. Higgins Research Foundation and the Melbourne Abroad Traveling Scholarships

\section{LITERATURE CITED}

Backhouse, G. N. \& J.A. Jeanes. 1995. The Orchids of Victoria. The Meigunyah Press, Melbourne.

Batty, A.L. 2001. The role of symbiotic seed germination and seed ecology in the conservation of selected Western Australian terrestrial orchids. PhD Thesis, Soil Science and Plant Nutrition, The University of Western Australia.

Batty, A.L., K.W. Dixon, M.C. Brundrett \& K. Sivasithanparam. 2001. Constraints to symbiotic germination of terrestrial orchid seed in a mediterranean bushland. New Phytol. 152: 511-520.

Batty, A.L., M.C. Brundrett, K.W. Dixon \& K. Sivasithanparam. 2006. In situ symbiotic seed germination and propagation of terrestrial orchid seedlings for establishment at field sites. Austral. J. Bot. 54: 375-381.

Clements, M., P.J. Cribb \& H. Muir. 1986. A preliminary report on the symbiotic germination of European terrestrial orchids. Kew Bull. 41: 437-445.

Ilyes, Z., S. Rudnoy \& Z. Bratek. 2005. Aspects of in situ, in vitro germination and mycorrhizal partners of Liparis loeselii. Acta Biol. Szegediensis 49: 137-139.

Jeanes, J.A. \& G.N. Backhouse. 2000. Pictorial Guide to Wild Orchids of Victoria Australia. Zoonectics, Seaford, Victoria.

Perkins, A.J. \& P.A. McGee. 1995. Distribution of the orchid mycorrhizal fungus, Rhizoctonia solani, in relation to its host, Pterostylis acuminata, in the field. Austral. J. Bot. 43: 565-575.

Rasmussen, H.N., T.F. Andersen, T.F. \& B. Johansen. 1990. Temperature sensitivity of in vitro germination and seedling development of Dactylorhiza majalis (Orchidaceae) with and without a mycorrhizal fungus. Pl. Cell Envir. 13: 171-177.

Rasmussen, H.N. \& D.F. Whigham. 1993. Seed ecology of dust seeds in situ: a new study technique and it application in terrestrial orchids. Amer J. Bot. 80: 13741378.

Magali Wright is a PhD student at the University of Melbourne studying use of mycorrhizal fungi in re-introduction of Caladenia species. She also works at the Royal Botanic Gardens, Melbourne, as and orchid conservation officer.

Garry French is a Strategic Planner with Parks Victoria and is involved in the management of Caladenia amoena and a number of other endangered orchid species at Plenty Gorge Park.

Rob Cross supervises the ex situ component of the Recovery Plans for Endangered Victorian orchids at the Royal Botanic Gardens, Melbourne in association with the Department of Sustainability and Environment (DSE).

Prof. Roger Cousens is a researcher and lecturer in the field of weed ecology. His main research interests are plant population biology; weed ecology; invasions, terrestrial orchids and the application of ecology to management decisions.

Sascha Andrusiak is a research assistant at the Burnley Campus of the University of Melbourne. Her main areas of interest are mycorrhiza and climate change.

Cassandra McLean is a researcher and lecturer at the University of Melbourne. Her research interests include using mycorrhizas to improve propagation of Australian native plants and using molecular techniques to identify non-sporulating fungi. 